\title{
Static, Modal \& Thermal Analysis of Engine Block
}

\author{
Mr. Rushikesh G. Kolhe \\ Department of Mechanical Engineering \\ JSPM Narhe Technical Campus \\ Pune, Maharashtra, INDIA \\ Mr. Saurabh D. Kashid \\ Department of Mechanical Engineering \\ JSPM Narhe Technical Campus \\ Pune, Maharashtra, INDIA
}

\author{
Mr. Pratik V. Kokate \\ Department of Mechanical Engineering \\ JSPM Narhe Technical Campus \\ Pune, Maharashtra, INDIA \\ Mr. Akshay Kadu \\ Department of Mechanical Engineering \\ JSPM Narhe Technical Campus \\ Pune, Maharashtra, INDIA
}

\begin{abstract}
The cylinder block is a combine structure containing various cylinders of reciprocating engine and most of their compassing structure. The pistons are reciprocating inside the cylinder of engine block. Generally, cylinder block forms a basic framework of engine. Its houses of engine cylinder which serves as bearing and guided for the piston reciprocating in them.

The cylinder block forms the basic framework of the engine, it houses the engine cylinders, which serve as bearings and guides for the pistons reciprocating in them. The analysis of the engine block is to be carried out to predict its behavior under static and dynamic loading. The cylinder block has to withstand the stresses and deformations due to loads acting on it. The solid model of the block is generated in CATIA V5 R21. The model is imported to ANSYS through IGES format. The quality mesh is prepared in ANSYS for converged solution and the solver set as ANSYS in which loads and boundary conditions are applied for analysis. By using different materials Aluminium, Grey cast iron. The static analysis is performed to predict the
\end{abstract}

Keywords-CATIA V5, ANSYS, Aluminimum Alloy, Gery Cast Iron, Static Analysis, Modal Analysis, Thermal Analysis, Engine Block

\section{I.INTRODUCTION}

Today finite element analysis is very important tool in engineering analysis field. Whether in mechanical engineering to designing auto engines, rolling mills, machine tools or in aerospace engineering the aerospace engineer interested in the

analysis of dynamics of an aero plane or temperature rise in the heat shield of a space shuttle or a metallurgist concerned about the influence of a rolling operation on the microstructure of a rolled product or civil engineer designing bridges, dams or an electrical engineer interested in analysis of the electromagnetic field in electrical machinery-all find the finite element method handy and useful.

The Engine Cylinder Block is the main integrated structure of the IC Engine and is also called as Engine Block [6]. All the Engine parts are mounted on it. It provides housing for cylinders, pistons, and it also gives passages for the coolant, lubricating oils, exhaust, and intake gases to pass over the Engine. It constitutes about 3 to $5 \%$ of the total weight of the average vehicle. It is usually a casting and well ribbed to support and distribute loads applied by the expansion of the combustion gases. It is also provided with water jackets to cool the Engine. Both the spark ignition cylinder block and compression ignition cylinder blocks are similar relatively heavier and stronger to withstand high compression ratios and internal pressure. The Cylinder Block is bored for cylinders for the pistons to reciprocate

Cast Iron and Aluminium Alloys are the most widely used materials to manufacture the cylinder block. Cast iron alloys are used because they contain good mechanical properties, low cost, and availability compared with other metals. But certain aluminium alloys contain most of the characteristics of cast iron but with low weight, and also aluminium alloy casted engine block gives a good surface finish and high machinability compared with cast iron alloys.

\section{METHODOLOGY}

The work is divided into main parts,

1. Designing and Modeling

2. Meshing

3. Analysis

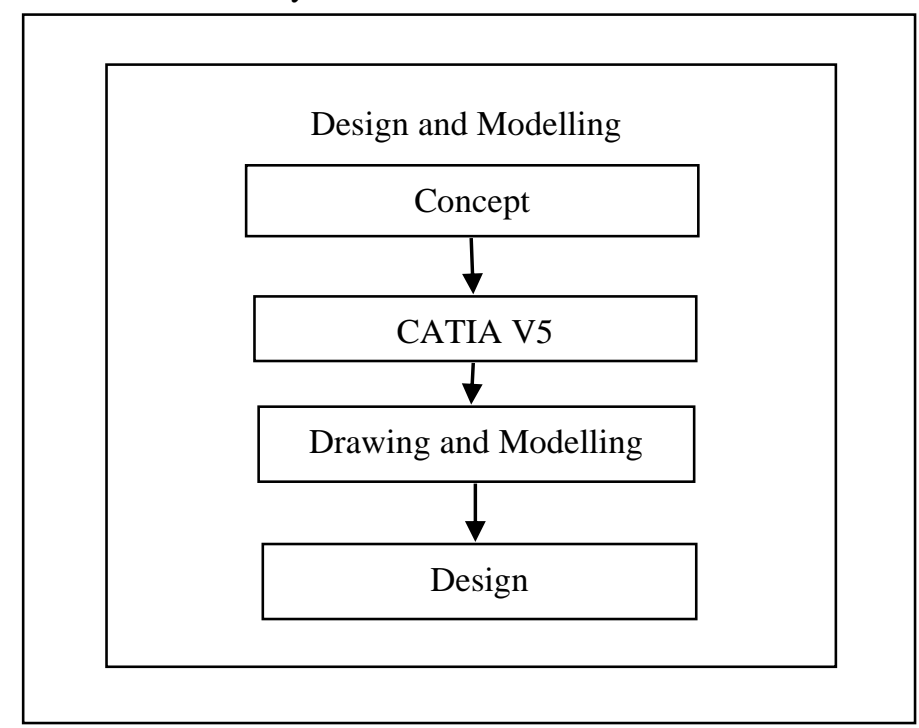




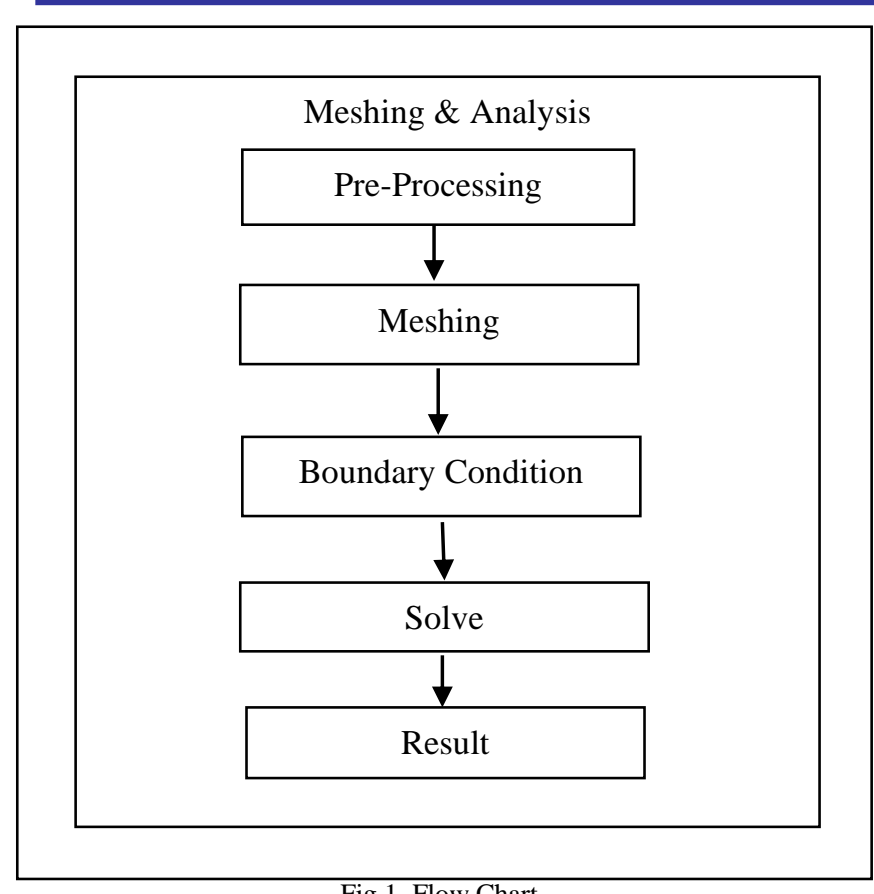

Fig 1, Flow Chart

\section{A. MODEING :-}

CATIA is a fully automation software which relates with the mechanical field. It is graphical user interface which is easy to learn and also the software is feature based and parametric solid modelling. We can draw 2D and 3D models of a part and accordingly the assembly of the parts can be done in it. The shape or geometry of the model or assembly is dependent upon the values which are referred as constraints. Modules such as sketcher module used to design $2 \mathrm{D}$ drawings, part design module is used to design the 3D models of geometry, and Assembly work design is used to assemble the different parts which are drawn in the part design module. Kinematics is used to give the simulation or motion to the part bodies which are designed and assembled in part and assembly design modules.

\section{- DIFFERENT MODULES USED IN CATIA}
1. Sketcher
2. Part Design
3. Assembly Design
4. Kinematics

By Using the CATIA software the part designs were designed because compared to other software's CATIA is easy to design.

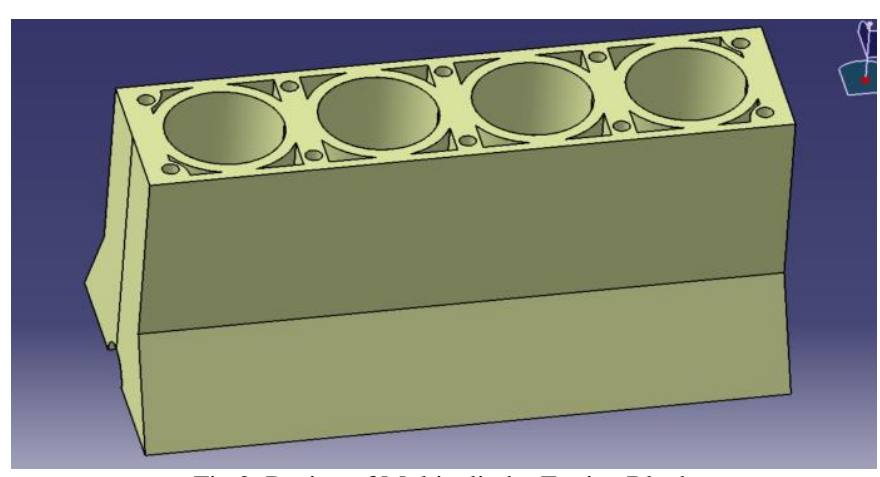

Fig 2, Design of Multicylinder Engine Block

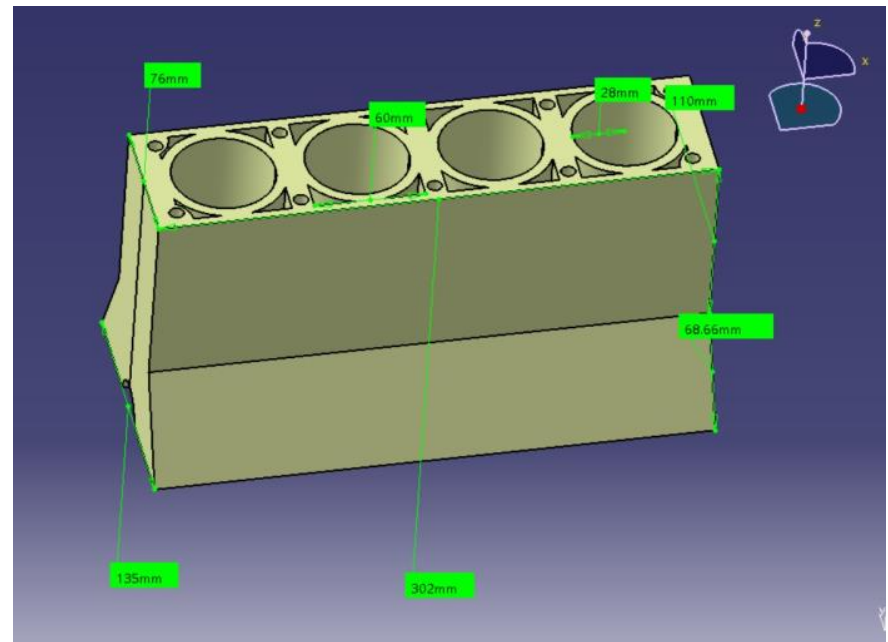

Fig 3, Diamensions of Multicylinder Engine Block

\section{B. MESHING :-}

The general concepts of meshing are simple, but that the practice of creating meshes that provide solid analysis results requires significant knowledge and experience. The first step in meshing is idealization of the CAD geometry. Typically, this encompasses simplifying the model, eliminating details that are not pertinent to analysis, or that have a marginal influence on the results. Once the model is ready, the next step is to create the mesh. The actual process to create the simulation model and the mesh will depend on which program is used. The end result of the process, will be a mesh made up of one or more forms of geometric elements. Any kind of analysis is only as good as the tools and processes used. A good mesh applies physics, with the understanding that things can change, and need to be taken into consideration during analysis.

Proper meshing allows for accurate analysis, regardless of whether the process is automated or manual. For any product development project to be successful, analysis is critical, and proper meshing is an important part of that analysis

The software used for meshing is Ansys, we use two meshing methods Patch conforming method and face meshing method. In patch conforming method we use tetrahedrane type and algorithm patch conforming

The geometry has 31722 no's of Nodes and 16894 no's of elements

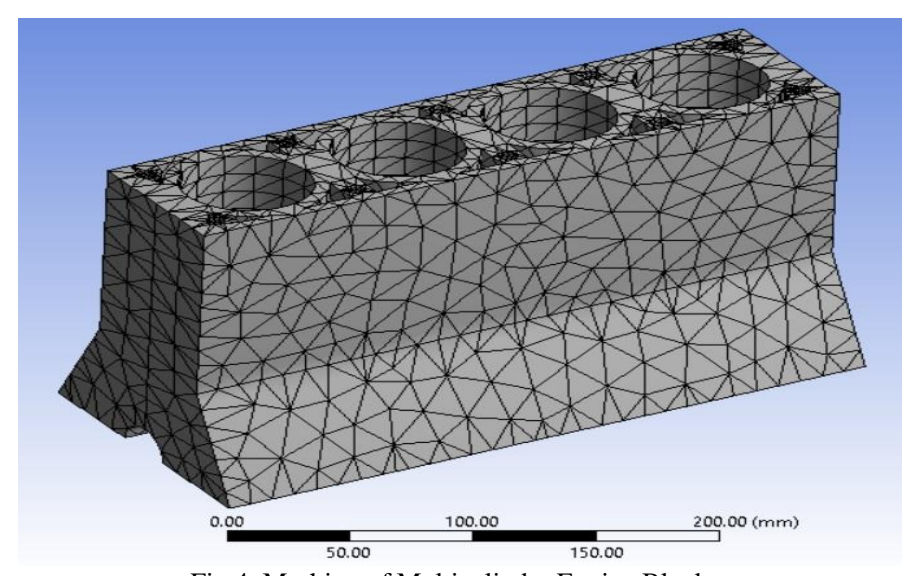

Fig 4, Meshing of Multicylinder Engine Block 


\section{FINITE ELEMENT ANALYSIS (FEA) :-}

The finite element method (FEM) (sometimes referred to as finite element analysis) is a numerical technique for finding approximate solutions of partial differential equations (PDE) as well as of integral equations. The solution approach is based either on eliminating the differential equation completely (steady state problems), or rendering the PDE into an approximating system of ordinary differential equations, which are then numerically integrated using standard techniques such as Euler's method, Runge-Kutta, etc. With the advance in the computer technology and CAD system, complex problem can be modified with relative ease. Several alternative configurations can be tested on a computer before the first prototype is built all of these suggests that we need to keep pace with these developments by understanding the basic theory, modelling techniques and computation aspect of the finite element.

The fundamental idea in FEA is that the body or structure may be separated into littler components of finite measurements called "Finite Elements". The original body or the structure is then considered as an array of these components associated at a limited number of joints called "hubs". Straightforward capacities are approximated the removals over each limited component. Such accepted capacities are called "shape capacities". This will signify the movement within the components as far as the relocation at the hubs of the components. The Finite Element method is a scientific tool for resolving ordinary and partial differential comparison in light of the fact it is a numerical tool, it can take care of the complex issue that can be signified in differential mathematical statement from. The use of FEM is limitless as respects the arrangement of down to earth design issues. Because of high cost of processing power of years passed by, FEM has a history of being utilized to take care of complex and expense critical difficulties.

\section{MATERIALS}

\section{- Gray Cast Iron :-}

Ordinary gas-fueled motor pieces. In spite of the fact that broad utilization of aluminum compounds has reduced the prominence of this material, regardless it finds wide use in diesel-fueled squares, where the inner anxieties are much higher. Dim cast press amalgams regularly contain 2.5-4 wt.\% carbon and 1-3 wt.\% silicon, 0.2-1.0 wt.\% manganese, $0.02-0.25$ wt. $\%$ sulfur, and $0.02-1.0 \mathrm{wt} . \%$ phosphorus [8]. It has magnificent damping limit, great wear and temperature resistance, is effectively machinable, and is economical to deliver. Nonetheless, dim cast irons are generally powerless and are inclined to crack and misshaping. Because of these issues, compacted graphite press has as of late contended with dark give press a role as the decision material to deliver diesel motor pieces. Figure 2 demonstrates the BMW S54 inline-6 utilized as a part of their elite M3 car. It is fascinating to note that the barrel hinder for this motor is built from dark cast press

\section{- Aluminum Alloys :-}

One of the key weight sparing elements in the motor plan is the utilization of a cast aluminum barrel obstruct with cast press chamber liners. The cast press liners (with ground outside-distance across) are press-fit into the accuracy exhausted aluminum barrel square. This gives ideal warmth move into the chamber piece. The iron liners give the wear resistance expected to enhanced toughness. The establishment procedure for the liners incorporates cooling the liner preceding position and refined exactness compel observing to guarantee legitimate establishment. After establishment, the ID of the iron liner is exhausted to a masssparing 1.5-millimeter divider thickness. Aluminum composite utilize has picked up ubiquity since the 1960's as an approach to lessen the general weight of the vehicle. There are two functional ramifications: enhanced execution toweight proportion and expanded fuel effectiveness. The downsides of utilizing aluminum in motor pieces are that they are more costly to produce than cast press amalgams. Be that as it may, the quality to-weight proportion of aluminum combinations is difficult to disregard, and assembling forms created during the time have minimized the cost difference amongst aluminum and cast press. There are two aluminum amalgams that are principally utilized as a part of the fabricate of chamber pieces: 319 and A356. Aluminum amalgam 319 has a structure of 85.8-91.5 wt.\% aluminum, 5.5-6.5 wt.\% silicon, 3-4 wt.\% copper, 0.35 most extreme wt.\% nickel, greatest 0.25 wt.\% titanium, most extreme 0.5 wt.\% manganese, most extreme $1 \%$ press, most extreme 0.1 wt. $\%$ magnesium, and greatest 1 wt. $\%$ zinc.

\section{ANALYSIS}

We are performed three analysis on the engine block at various conditions we are discuss on this

\section{Static Analysis:}

The basic finite element equation to be solved for structures experiencing static loads can be expressed as:

Where, $\mathrm{K}$ is the stiffness matrix of the structure (an assemblage of individual element stiffness matrices). The vector $\mathrm{u}$ is the displacement vector, and $\mathrm{P}$ is the vector of loads applied to the structure. The above equation is the equilibrium of external and internal forces. The equilibrium equation is solved either by a direct or an iterative solver. By default, the direct solver is invoked, whereby the unknown displacements are simultaneously solved using a Gauss elimination method that exploits the sparseness and symmetry of the stiffness matrix, $\mathrm{K}$, for computational efficiency. Alternatively, an iterative solver using the preconditioning conjugate gradient method may be used. While the direct solver is very robust, accurate and efficient, the iterative solver is sometimes superior, in terms of speed, for thick-walled solid structures. The structure's behavior is linear (must obey Hooke's Law). Linear static analysis has two main assumptions:

1.Forces are linearly proportional to deformation. If you double the loads, the response (displacements, strains, stresses) also double. Stress is proportional to strain.

2.When the loading is removed the material must return to its original shape. (No plastic deformation).

3.Boundary conditions do not vary during the application of loads. Time varying loads, Dynamic loads, Vibrations, Temperature cannot be applied in Linear Static. 
For Aluminum Alloy,

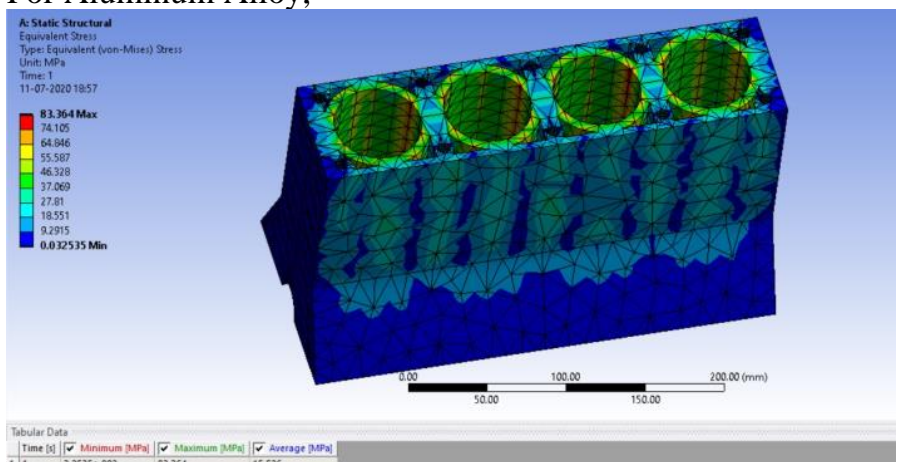

Fig 5, Equvalent Stress

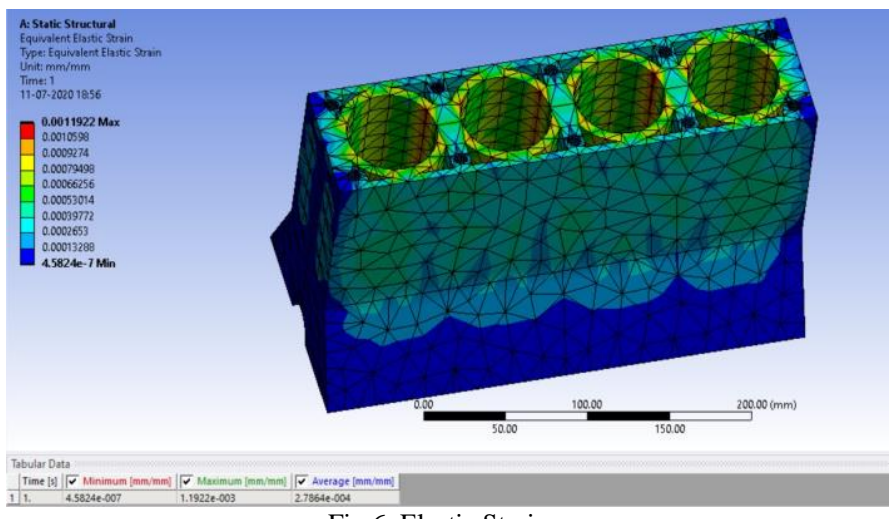

Fig 6, Elastic Strain

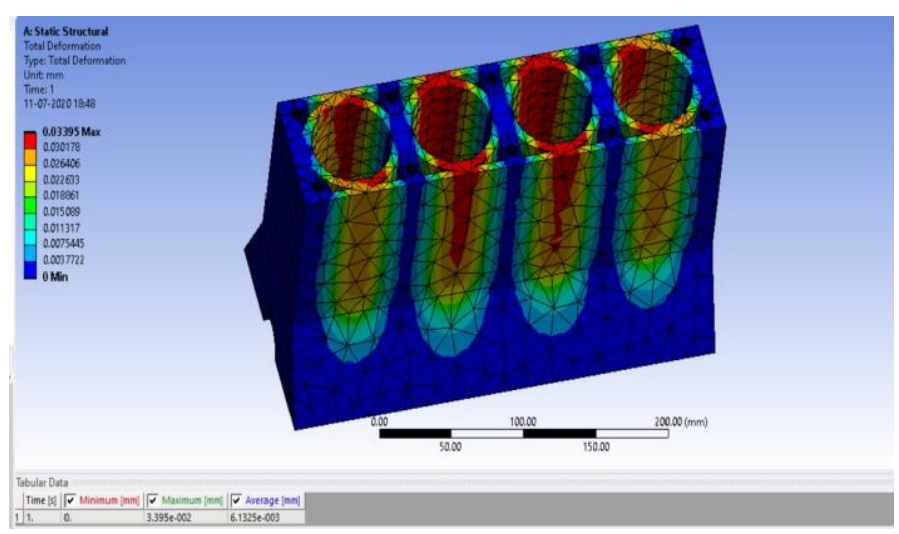

Fig 7, Total deformation

For Grey Cast Iron,

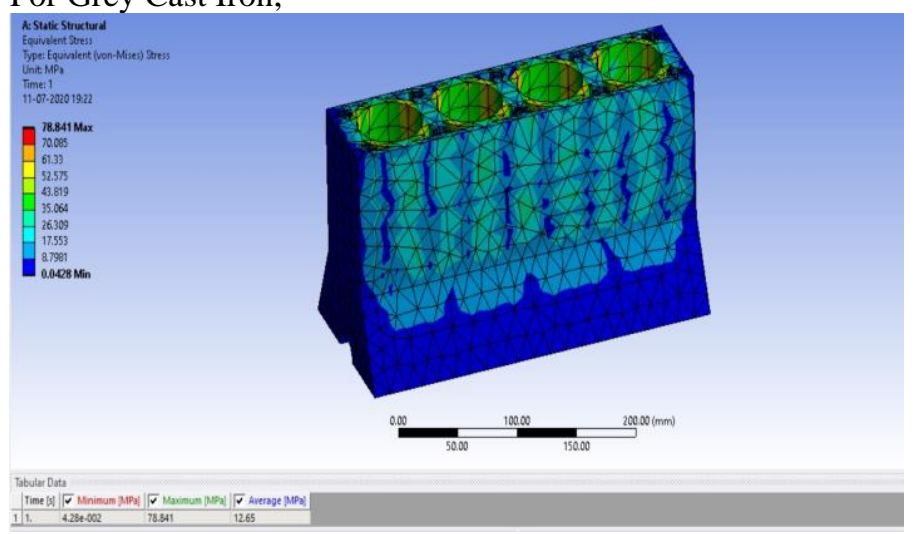

Fig 8, Equvalent Stress

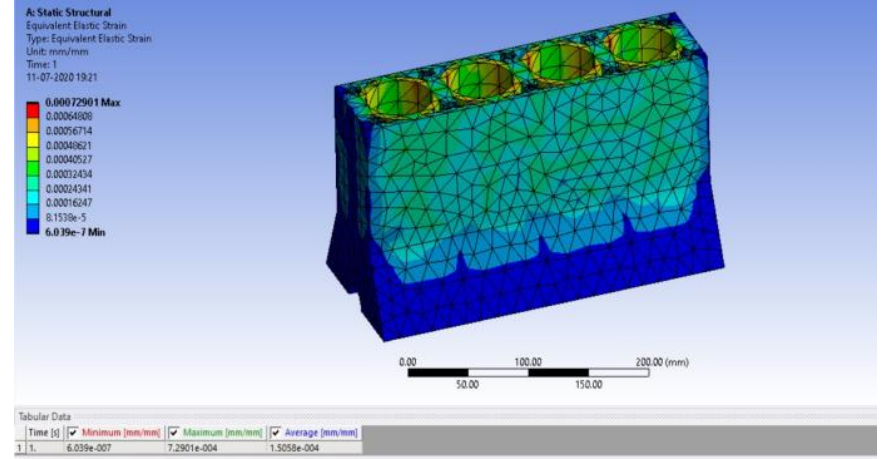

Fig 9, Elastic Strain

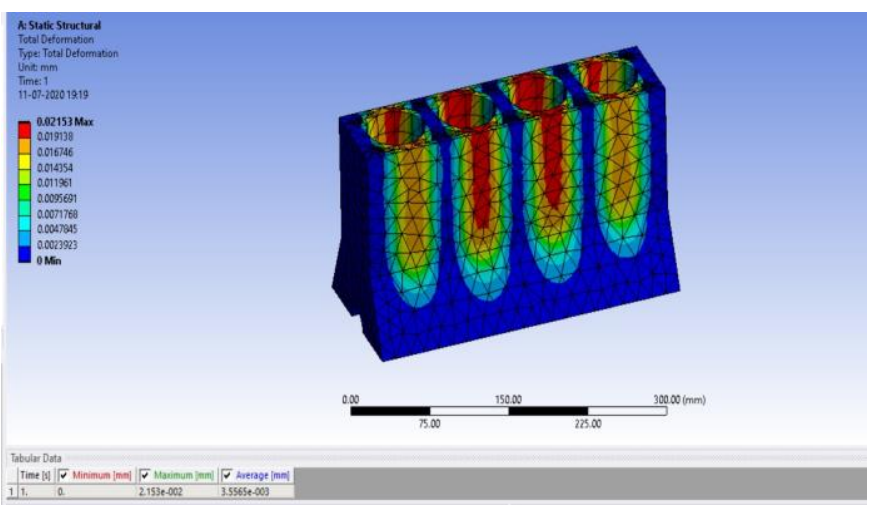

Fig 10, Total Deformation

\begin{tabular}{|c|c|c|c|}
\hline Materials & Deformation (mm) & $\begin{array}{c}\text { Von mises } \\
\text { Stress (MPa) }\end{array}$ & $\begin{array}{c}\text { Elastic strain } \\
(\mathbf{m m} / \mathbf{m m})\end{array}$ \\
\hline $\begin{array}{c}\text { Gray Cast } \\
\text { Iron }\end{array}$ & 0.0215 & 78.84 & 0.00072 \\
\hline $\begin{array}{c}\text { Aluminum } \\
\text { Alloy }\end{array}$ & 0.03395 & 83.36 & 0.001192 \\
\hline
\end{tabular}

Table 1 Deformations, stresses, strian

2. Modal Analysis: -

Certain properties of a component do not change with respect to the changes in the Initial conditions of the component. Such properties can be termed as Characteristics Solutions.

They are;

1) Natural Frequencies

2) Modes of Vibration

Natural Frequencies: The frequencies that occur in free motion of the component i.e. the component is not subjected to any external loading or vibrations is called as natural frequencies. Modes of Vibration: The component will deform in different directions at corresponding different frequencies. These different directions of deformations are known as Modes of Vibration. The Natural Frequencies and the Modes of vibrations constitutes the Characteristic Solutions. In Modal Analysis we find out the values of Natural Frequencies and modes of vibrations. The natural frequencies of a component are extracted in order to avoid the Resonance condition which can occur if natural frequencies of components match with the excitation frequencies. Therefore, extracting the natural frequencies of components and keeping them away from excitation frequencies will reduce the chances of resonance condition where the component will deform at its maximum amplitude. 
For Aluminum Alloy,

\begin{tabular}{|c|c|c|c|c|}
\hline $\begin{array}{c}\text { Mode } \\
\text { No }\end{array}$ & $\begin{array}{c}\text { Natural } \\
\text { Frequency }(\mathbf{H z})\end{array}$ & \multicolumn{3}{|c|}{ Total Deformation (mm) } \\
\cline { 3 - 5 } & 6739.8 & 275.3 & 0 & Mvg \\
\hline 1 & 6918 & 275.3 & 0 & 1.5967 \\
\hline 2 & 7012.4 & 273.4 & 0 & 1.5967 \\
\hline 3 & 7206.3 & 271.5 & 0 & 1.6527 \\
\hline 4 & 8668 & 418.87 & 0 & 1.1829 \\
\hline 5 & \multicolumn{4}{|c}{} \\
\hline
\end{tabular}

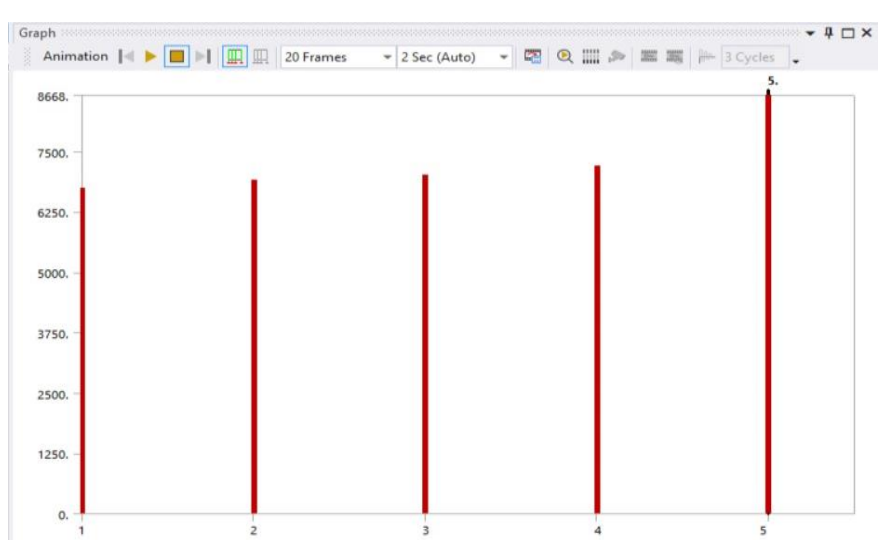

Fig 11, Frequency VS Mode

For Grey Cast Iron,

\begin{tabular}{|c|c|c|c|c|}
\hline Mode & Natural & \multicolumn{3}{|c|}{ Total Deformation (mm) } \\
\cline { 3 - 5 } No & Frequency (Hz) & Max & Min & Avg \\
\hline 1 & 5165.2 & 169.2 & 0 & 0.9881 \\
\hline 2 & 5289.7 & 169.2 & 0 & 0.9881 \\
\hline 3 & 5369.7 & 164.91 & 0 & 0.9602 \\
\hline 4 & 5503.6 & 166.86 & 0 & 0.9975 \\
\hline 5 & 6637.5 & 162.57 & 0 & 0.9737 \\
\hline \multicolumn{5}{|c}{ Table 3 }
\end{tabular}

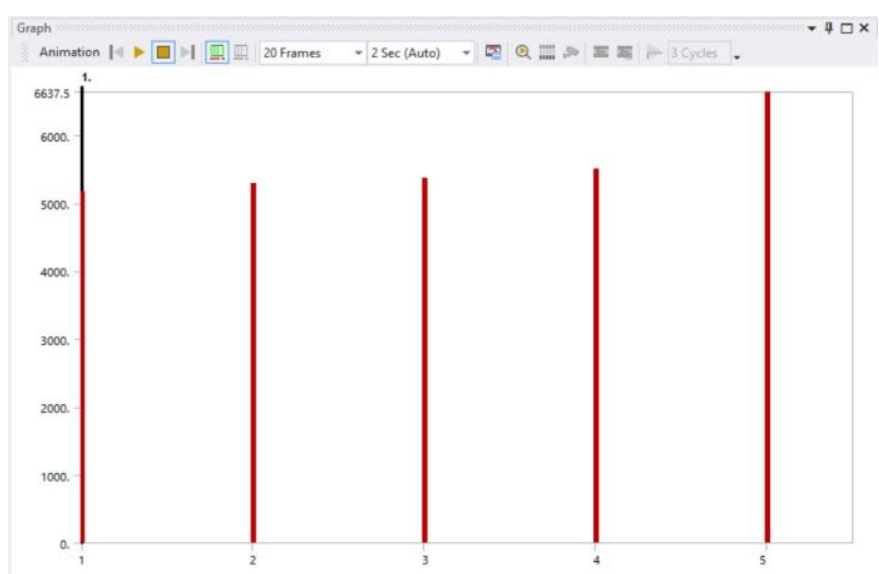

Fig 12, Frequency VS Mode

3. Thermal Analysis: -

Generally, the performance of vehicles mainly depends on the performance of engine. The selection of best engine design and manufacturing is mainly depending on the selection of materials because internal combustion engines performance directly related to thermal behaviour of the materials. Thermal analysis is the branch of material science that investigates the properties of materials that are involved in thermal analysis and also subjected to change with change in temperature. Thermal analysis is also often used for studying of heat transfer through the structures like internal combustion engines, moulding blocks and in many more applications where ever heat transfer takes place with conduction and convection modes. In this paper an attempt has been made to find out the best material that is used for cylinder block of bike.

We perform thermal analysis for temperature distribution, total heat flux, directional heat flux

For Aluminum Alloy,

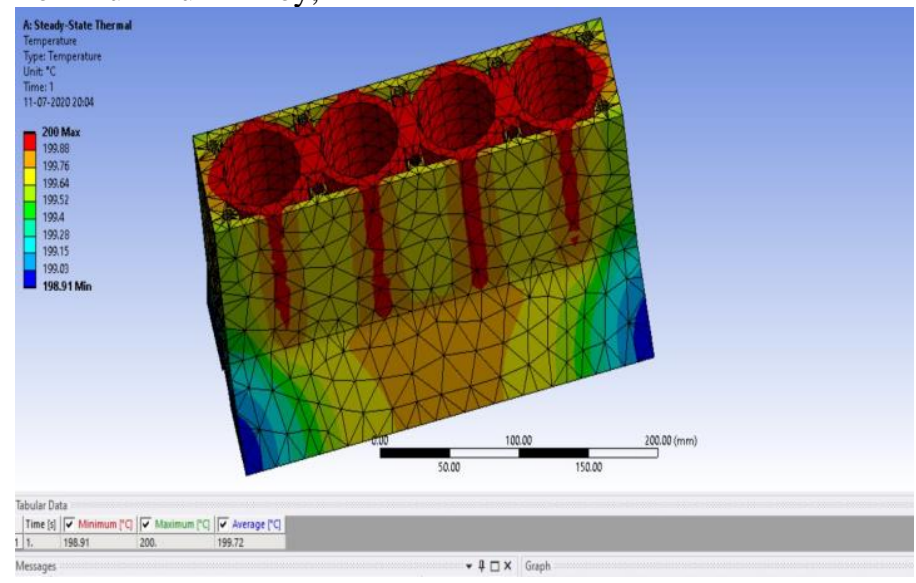

Fig 13, Tempratue Disribution

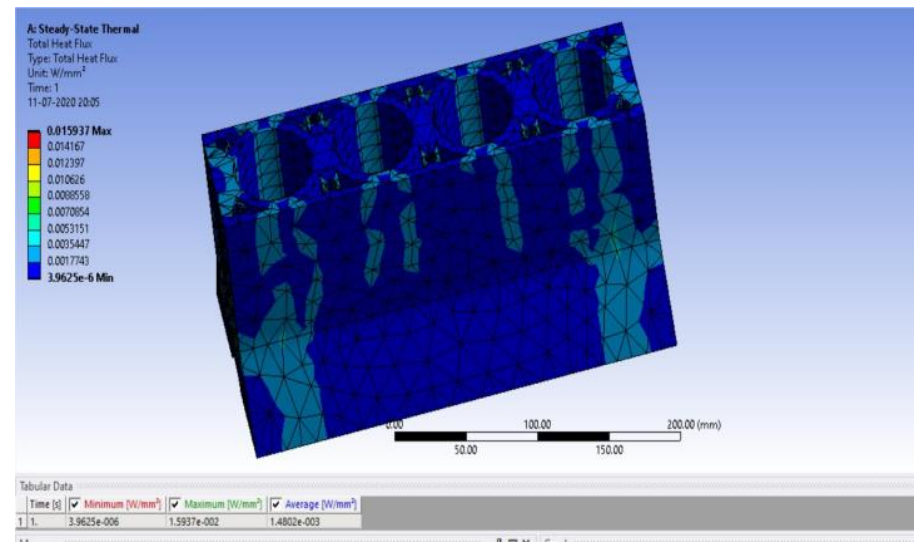

Fig 14, Total heat flux

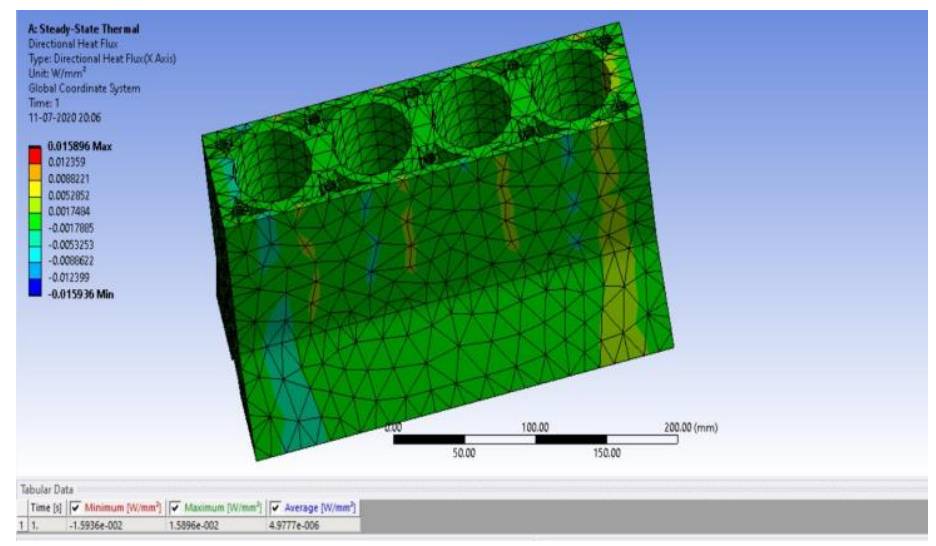

Fig 15, Directional Heat Flux 


\section{For Grey Cast Iron,}

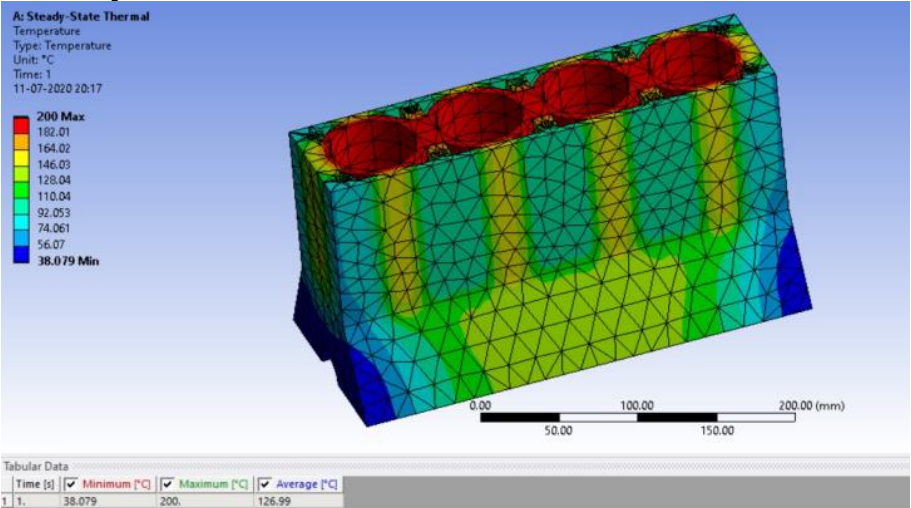

Fig 16, Tempratue Disribution

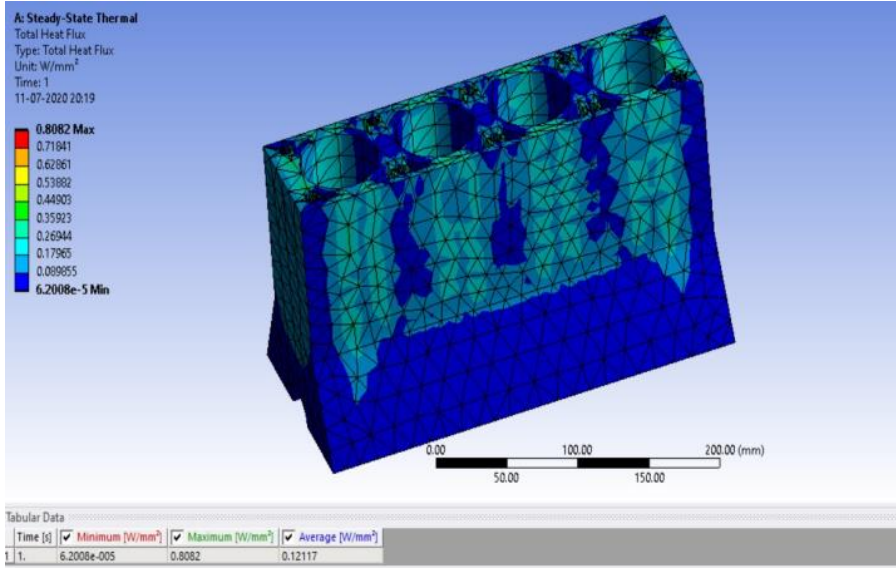

Fig 17, Total heat flux

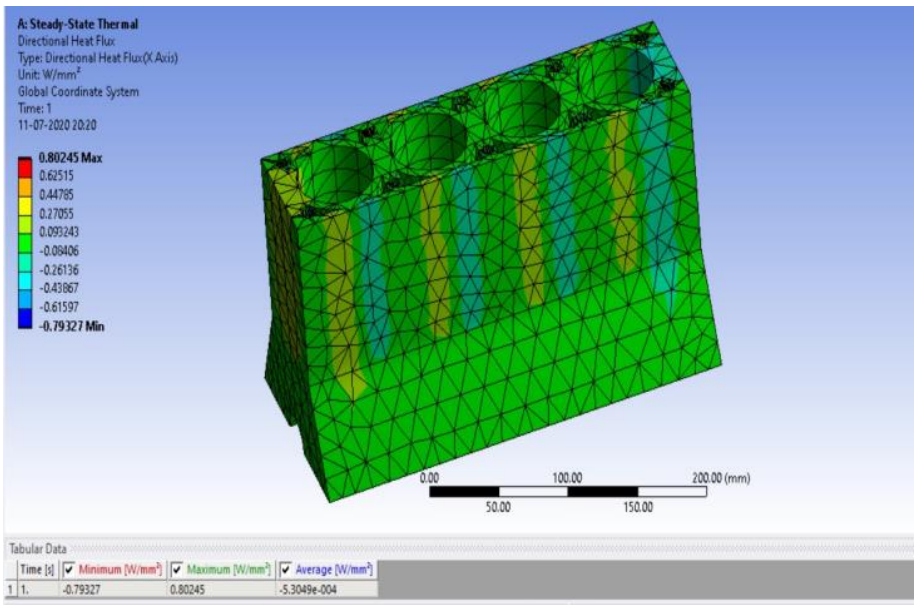

Fig 15, Directional Heat Flux

\section{RESULT AND CONLUCION}

The following conclusions are concluded from the present analysis
1. The deformations of engine block are obtained for different materials out of which aluminium alloy has the least deformation, which is $0.033 \mathrm{~mm}$ based on the value of aluminium alloy. The von mises stresses are obtained for both materials out of which the stress induced in Gray cast iron is less, which is 84.3 $\mathrm{MPa}$. Based on the design criteria this value is less than the yield strength value and factor of safety is less, hence the design is safe based on strength criteria.

2. The model analysis is performed to predict five natural frequencies and their corresponding mode shapes of five different materials out of which aluminium has the highest excitation.

3. The frequencies for the aluminium engine block are $6739.8 \mathrm{~Hz}, 6918 \mathrm{~Hz}, 7012.4 \mathrm{~Hz}, 7206.3 \mathrm{~Hz}$ and $8668 \mathrm{~Hz}$

4. The thermal analysis is performed for to predict the thermal behaviour of the material the observations is made that aluminium alloy has less heat flux counted to $0.01593 \mathrm{~W} / \mathrm{mm}^{2}$ and directional heat flux is counted to $0.01589 \mathrm{~W} / \mathrm{mm}^{2}$

\section{REFERENCES}

[1] "Thermal Analysis of cylinder block with fins for different materials using ANSYS" Obula Reddy Kummitha**, B.V.R. Reddyb a,bAssistant Professor, Department of Mechanical Engineering, Gitam University, Hyderabad-502329, India

[2] "Design and Analysis of Four Cylinder Engine Block by Using F.E.A" by Mukesh Annamneedi, Jithendra, IJMETMR, Volume no :3 (2016)< issue no : 9 (sept)

[3] MODELING \& ANALYSIS OF ENGINE BLOCK D. R. Parthasarathi1, Y. Srinath2, S. Madhusudhana3 ISSN (PRINT): 23938374, (ONLINE): 2394-0697, VOLUME-4, ISSUE-11, 2017

[4] DESIGN AND ANALYSIS OF CYLINDER HEAD OF AN ENGINE Vishal Sapkal\#1, Kamal Ukey\#2 International Research Journal of Engineering and Technology Volume: 05 Issue: 05 | May-2018

[5] A FEM Investigation for I C Engine Cylinder Block by Varying Thicknesses of Water Jacket 2017 IJEDR | Volume 5, Issue 1 | ISSN: 2321-9939

[6] Modal Analysis of V-12 Engine Cylinder Block Using Abaqus Software for Different Materials. International Journal of Recent Technology and Engineering (IJRTE) ISSN: 2277-3878, Volume-7, Issue-ICETESM, March 2019

[7] THERMOMECHANICAL ANALYSIS OF ENGINE BLOCK OF ICENGINE Suresh R1, Anil Kumar B N2, Shyam Sunder N3, Shridhar Deshpande International Journal For Technological Research In Engineering Volume 2, Issue 11, July-2015

[8] DESIGN AND THERMAL ANALYSIS OF CYLINDER BLOCK T. Rohith Goud1, Mohd. Naseeruddin2, C. Raghavendra3, Jyotsna Santhi4 IJARSE volume no : -6 issue no :- 1 january 2017

[9] MODELING \& ANALYSIS OF ENGINE BLOCK D. R Parthasarathi1, Y. Srinath2, S. Madhusudhana3 ISSN (PRINT): 23938374, (ONLINE): 2394-0697, VOLUME-4, ISSUE-11, 2017 